
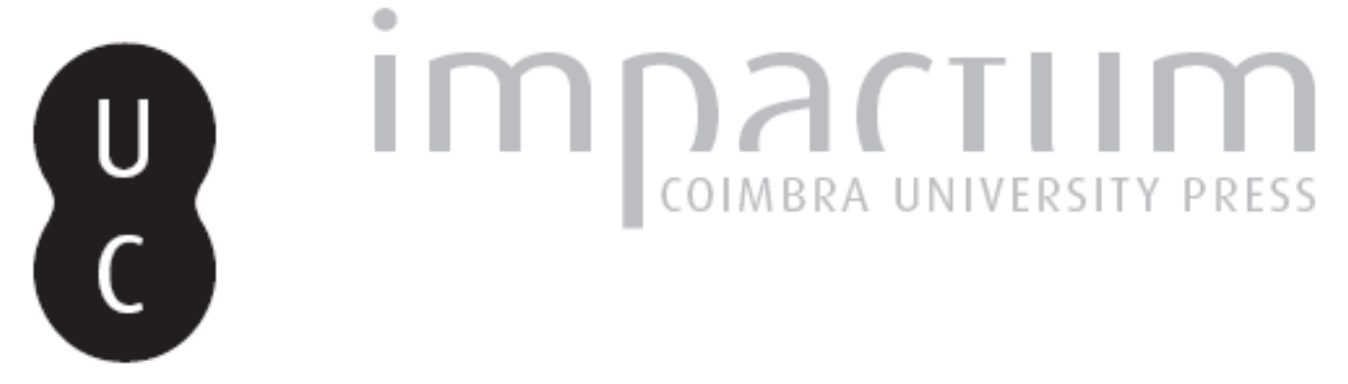

\title{
Território, fronteira e expansão no período meso-asiático: a presença assíria no
} Eufrates Médio

\author{
Autor(es): $\quad$ Caramelo, Francisco \\ Publicado por: Centro de História da Universidade de Lisboa \\ URL \\ persistente: \\ URI:http://hdl.handle.net/10316.2/23459 \\ DOI: \\ DOI:http://dx.doi.org/10.14195/0871-9527_21_2
}

Accessed : $\quad$ 26-Apr-2023 06:08:04

A navegação consulta e descarregamento dos títulos inseridos nas Bibliotecas Digitais UC Digitalis, UC Pombalina e UC Impactum, pressupõem a aceitação plena e sem reservas dos Termos e Condições de Uso destas Bibliotecas Digitais, disponíveis em https://digitalis.uc.pt/pt-pt/termos.

Conforme exposto nos referidos Termos e Condições de Uso, o descarregamento de títulos de acesso restrito requer uma licença válida de autorização devendo o utilizador aceder ao(s) documento(s) a partir de um endereço de IP da instituição detentora da supramencionada licença.

Ao utilizador é apenas permitido o descarregamento para uso pessoal, pelo que o emprego do(s) título(s) descarregado(s) para outro fim, designadamente comercial, carece de autorização do respetivo autor ou editor da obra.

Na medida em que todas as obras da UC Digitalis se encontram protegidas pelo Código do Direito de Autor e Direitos Conexos e demais legislação aplicável, toda a cópia, parcial ou total, deste documento, nos casos em que é legalmente admitida, deverá conter ou fazer-se acompanhar por este aviso.

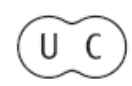



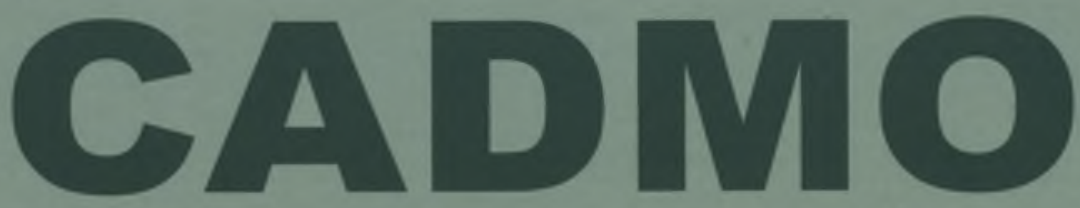

Revista de História Antiga

\author{
Centro de História \\ da Universidade de Lisboa
}

\title{
21
}

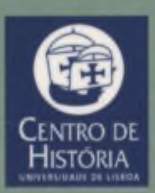

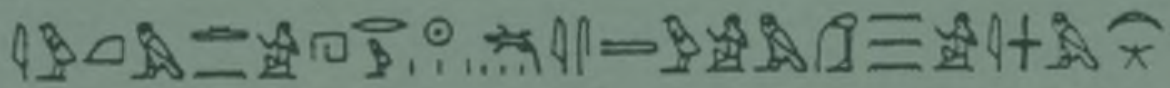

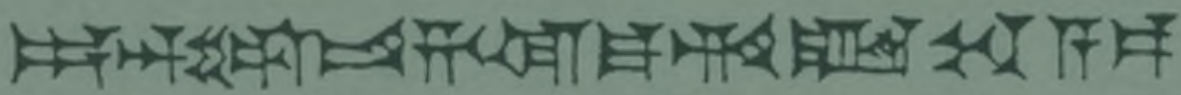

MHNIN AEI $\Delta \mathrm{E} \Theta \mathrm{EA}$ ПH$\Lambda \mathrm{HIA} \triangle \mathrm{E} \Omega$ 


\title{
TERRITÓRIO, FRONTEIRA E EXPANSÃO NO PERÍODO MESO-ASSÍRIO. A PRESENÇA ASSÍRIA NO EUFRATES MÉDIO
}

\author{
FRANCISCO CARAMELO \\ Universidade Nova de Lisboa \\ F.Caramelo@gmail.com
}

\section{A construção de uma nova arquitectura geopolítica}

Dominada pelo Mitanni ou Hanigalbat, a Assíria começa, no séc. XIV a. C., a afirmar-se no contexto internacional da Mesopotâmia, saindo de uma certa obscuridade que caracterizara os séculos anteriores ${ }^{1}$. O reinado de Aššur-uballiț I (c. 1363-1328)2 assinala de forma clara essa transição cujo eixo decisivo consiste na restauração da independência do país. Esse meio século assiste à construção de um novo equilíbrio geopolítico em que a Assíria passará, sobretudo nos reinados de Adad-nîrârî I, Salmanazar I e Tukultî-Ninurta I, de estado vassalo a potência dominante na região entre o Tigre e o Eufrates.

No quadro do chamado sistema Amarna ${ }^{3}$, Aššur-uballiț procura emergir como um interlocutor do Egipto. A iniciativa diplomática, reflectida nas cartas de Amarna EA 15 e EA $16^{4}$, traduz, por um lado, a confirmação de que a Assíria é já um estado livre da soberania do Mitanni e, por outro, que tem a intenção de se afirmar no contexto internacional. A primeira carta tem uma índole exploratória. O rei assírio tenta ser reconhecido como interlocutor e procura estabelecer um diálogo político directo com o Egipto. A segunda carta reflecte já um estádio mais avançado nas 
relações políticas entre os dois reinos. Aššur-uballiț interpela o faraó como "grande rei» (šarru rabû) e atribui a si próprio o mesmo epíteto. Este reconhecimento mútuo mostra evidentemente os interesses que o Egipto e a Assíria têm em comum. AAssíria tem como objectivo estratégico a consolidação da sua posição, a eventual anexação dos territórios que derivem do colapso do Mitanni e o Egipto não desdenharia certamente a possibilidade de o estado mesopotâmico poder apoiá-lo numa frente comum contra o Hatti.

Na verdade, o Hatti não foi alheio ao declínio rápido do Mitanni, permitindo a consequente libertação e ascensão da Assíria ${ }^{5}$. Os hititas não tinham qualquer interesse numa aliança estratégica entre o Mitanni e o Egipto ${ }^{6}$. Suppiluliuma I (1344-1322 a.C.) concretiza, ao longo do seu reinado, uma série de confrontos com o Mitanni, conduzindo-o inexoravelmente ao seu ocaso na cena política internacional. Numa primeira fase, Aššur-uballiț, sobretudo como espectador, beneficiará dos ventos favoráveis que lhe chegam desse conflito, vendo aliviar-se a pressão do suserano. Não obstante, num segundo momento, como demonstra EA 15 , o rei assírio parece sentir-se suficientemente seguro para entabular contactos directos com o faraó. O Egipto, por outro lado, percebendo o declínio imparável do seu aliado de outros tempos, aceita Aššur-uballiț como seu novo interlocutor, reconhecendo o estatuto de "grande rei» que este ambicionava. Doravante, o Mitanni permanecerá isolado e moribundo entre os seus dois inimigos, que partilharão entre si o seu território.

A decadência do Mitanni leva a um novo equilíbrio político e militar mas a lógica estratégica das grandes potências manter-se-á inalterável. $\mathrm{Na}$ verdade, o Egipto continuará interessado num aliado transeufratense e a Assíria parece, nesta abordagem diplomática (EA 15 e EA 16), empenhada em estabelecer relações políticas com o faraó, antecipando possivelmente a futura animosidade do Hatti, uma vez que a potência mesopotâmica tenderia a substituir o Mitanni $^{7}$ no equilíbrio geopolítico emergente, disputando com os hititas o território do agonizante país. No fundo, inverteram-se os papéis. Nesta geometria variável, desfazem-se as alianças de outrora e urdem-se novos entendimentos. O inimigo de antes, o Mitanni, transfigura-se em novo aliado dos hititas.

O resultado dos ataques hititas ao Mitanni foi um cenário de disputas dinásticas e um vazio político ${ }^{8}$ que se tornariam incómodos para Suppiluliuma. O tratado entre Šattiwaza e Suppiluliuma ${ }^{9}$ testemunha a intervenção hitita nos assuntos internos do Mitanni, apoiando um dos pretendentes ao trono em Waššuganni. Traduz, no entanto, também a evidente desigualdade de estatuto político entre ambos. Suppiluliuma vangloria-se de haver acolhido o 
príncipe, filho de Tušratta, fugido do seu próprio país, e de o ter entronizado, restabelecendo a ordem e salvando o Mitanni ${ }^{10}$.

Nesta nova arquitectura geopolítica, Aššur-uballiț passou de monarca submisso e de vassalo do Hanigalbat a "grande rei», com reconhecimento entre as potências do seu tempo. O declínio do Mitanni, que resultou da pressão hitita, teve como consequência o estabelecimento de novas alianças políticas e militares. Observa-se um processo de regeneração do equilíbrio geopolítico, com uma geometria diferente da que se apresentava anteriormente. A lógica estratégica, apesar dessa geometria variável, permanece idêntica. Na verdade, o Egipto continua a desejar e a precisar de um aliado transeufratense e a Assíria emerge, na sequência da decadência da potência hurrita, como bom candidato a essa posição. A aproximação estratégica entre a Assíria e o Egipto, iniciativa de mútuo interesse, teria efeitos lógicos no outro eixo do sistema. O Hatti procurará agora regenerar o Mitanni, tentando que este, sob a sua suserania, funcionasse como estado-tampão e permitisse equilibrar a relação com o Egipto. Contudo, a Assíria desequilibrará o sistema ao desenvolver um processo expansionista que a fará procurar novas áreas de exploração económica a ocidente, na região eufratense. Beneficiará da desintegração do estado hurrita e entrará em choque directo com o Hatti, tornando-se uma grande potência.

\section{A mudança de paradigma ideológico}

Entre os séculos XIV e XIII a. C., lançadas as bases de uma nova arquitectura geopolítica, a Assíria alterará o seu paradigma ideológico. Parece, não obstante, confirmar-se a ideia de que a assunção de novos programas ideológicos está necessariamente vinculada a uma realidade política que os justifica minimamente. Queremos com isto dizer que novas titulaturas, epítetos reais ou formulações inovadoras não ocorrem, em princípio, se não tiverem um mínimo de sustentação. Na verdade, neste período, regista-se a consonância entre este recente paradigma ideológico e um novo horizonte político. Uma Assíria expansionista justifica um paradigma ideológico mais ambicioso ${ }^{11}$.

A primeira ruptura com o passado recente consistiu na evolução definitiva de um paradigma político caracterizado pela cidade-estado para um paradigma de estado territorial ${ }^{12}$. É evidente que isto não significa que o processo histórico tenha sido brusco ou que a cidade-estado não tivesse, também ela, uma base territorial. $O$ que acontece é que no caso 
da cidade-estado prevalecia uma lógica urbana, confinada a um espaço mais circunscrito e essa realidade condicionava a matriz ideológica e a identidade política da Assíria. A cidade-estado como organização política tinha o seu território, contudo, a sua dimensão limitada, a sua proximidade e o facto de aquele coincidir em grande medida com a própria cidade determinavam a mundividência urbana. A relação do poder e até da divindade poliade com a cidade eram estruturantes e isso definia necessariamente a ideologia real.

A evolução progressiva desse paradigma da cidade-estado para o paradigma de estado territorial conduziu à produção de uma renovada semântica política no poder real assírio, a qual em vários aspectos retomava epítetos já usados em épocas anteriores. Após Aššur-uballiț e sobretudo no séc. XIII a.C., o expansionismo assírio e a agressividade quase programática que caracterizam a Assíria desse período têm consequências na linguagem do poder. É nas inscrições reais, sobretudo as que correspondem aos reinados de Adad-nîrârî I, de Salmanazar I e de Tukultî-Ninurta I, onde melhor podemos observar a pluralidade de títulos reais e as tendências ideológicas e programáticas. Perspectivamos esses títulos ou epítetos em duas lógicas distintas. Poderíamos dizer que a primeira apresenta uma índole nacional. Títulos como ŠID dAššur, isto é, o vice-regente de Aššur, ou šakni Enlil, isto é, nomeado por Enlil, não sendo originais, têm sobretudo uma lógica religiosa-nacional, uma vez que associam o exercício do poder e a sua legitimidade a divindades tutelares e centrais na identidade fundacional da Assíria ${ }^{13}$.

A lógica nacional tem, todavia, outras cambiantes igualmente relevantes na construção de uma identidade assíria de base territorial. Nesse sentido, encontramos títulos como PA (waklu), inspector, e LUGAL em títulos

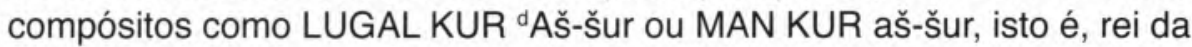
Assíria. Podemos observar nestes últimos dois casos uma associação do poder real (LUGAL e MAN) a um referente mais territorial (KUR). O conceito de território, aqui o país de Aššur, é decisivo nesta análise. Efectivamente, e não será por acaso, Aššur-uballiț usa pela primeira vez o título de LUGAL KUR ${ }^{\mathrm{d} A s ̌-s ̌ u r ~(s ̌ a r ~ m a ̄ t ~ A s ̌ s ̌ u r) . ~ F a ́-l o ~ q u e r ~ e m ~ a u t o-r e f e r e ̂ n c i a s ~ p a r a ~ c o n s u m o ~}$ interno, designadamente na utilização do seu próprio selo, quer também nas missivas que endereça ao faraó e que já mencionámos. De forma algo variável, a Assíria foi construindo uma identidade enraizada num território de referência ${ }^{14}$ que leva Aššur-uballiț a reflectir esse sentido da territorialidade na inovação que introduz na titulatura real.

A configuração político-territorial da Assíria depois de Aššur-uballiț e a consequente dimensão ideológica que Ihe subjaz concretizam a 
importância do território e da sua expressão supra-urbana na construção de uma renovada identidade nacional. A percepção de um território que ultrapassa o horizonte da urbe, resultado do programa expansionista iniciado no século XIV a. C., altera necessariamente o sentido dessa identidade, já não exclusivamente centrada na cidade. Essa consciência de uma nova territorialidade não podia deixar de ter consequências na expressão ideológica e na semântica do poder. O epíteto que Aššur-uballiț usa ao interpelar o faraó, šarru rabû («grande rei»), é possível porque aquele se sente justificado pelas suas conquistas e pelo território que administra. Os outros epítetos já evocados reflectem essa consciência e essa realidade supra-urbana.

A verdadeira inovação introduzida por Aššur-uballiț é, efectivamente, a referência ao "país de Aššur " como uma realidade supra-urbana, reflectindo dessa forma um sentido da territorialidade que é decisivo na consciência da identidade e na afirmação do novo programa político e ideológico. Os outros títulos manifestam-se de forma recorrente na Mesopotâmia. Não são títulos originais nem especificamente assírios. Diríamos que são títulos que definem uma identidade mesopotâmica, não exclusivamente assíria. Essa assunção de uma identidade cultural e política supra-assíria, que, neste contexto, os assírios assumem e interiorizam, reflecte, como noutras ocasiões e de forma recorrente, a legitimação de uma intenção, de um programa e de uma acção política e militar.

A recorrência destes títulos tem inerente o que poderíamos definir como um realismo mínimo ${ }^{15}$. Efectivamente, no contexto que nos ocupa, observamos que a evocação de epítetos e de títulos de horizonte supra-assírio e mesopotâmico tornam a verificar-se no reinado de Aššuruballiț, numa época em que a Assíria, depois de se libertar do seu antigo suserano, o Hanigalbat, adquire uma dinâmica expansionista. Essa dinâmica de conquista conduz a uma segunda lógica, que poderíamos definir como uma lógica supranacional. O rei assírio assume títulos recorrentes e já usados em contextos anteriores que exprimem uma ambição de dominação universal. Destacam-se epítetos reais como "rei da totalidade", šar kiššati, e "rei das quatro regiões", šar kibrât arba'i. Como já afirmámos, não é a primeira vez que estes títulos são usados na Mesopotâmia e também não será a última. A conquista da Mesopotâmia setentrional permitiu justificar aquilo que designámos por "realismo mínimo".

No contexto expansionista dos séculos XIV e XIII a. C., a Assíria vence o Mitanni, a antiga potência suserana, e anexa boa parte do seu território, na Mesopotâmia setentrional. Mais tarde, derrota a Babilónia cassita, a sul, e expande-se para ocidente, dominando a jazira, até às 
margens do Habur, do Balih e do Eufrates. É neste contexto que o rei assírio se sente legitimado não apenas para ombrear com os principais e mais prestigiados soberanos do tempo como para envergar títulos ambiciosos e patrocinar a produção de inscrições que nos parecem eivadas de irrealismo. Contudo, quer a titulatura quer as inscrições devem ser compreendidas e interpretadas do ponto de vista da sua hermenêutica interna. Nesse sentido, supõem um registo de intencionalidade e uma declaração programática, ambos fundamentados pela tendência expansionista e pelas conquistas efectuadas.

Um outro título traduz de forma muito clara a importância de uma nova percepção da territorialidade na visão política dos assírios. A expressão, sob a forma de uma perífrase, "aquele que expande os territórios e as fronteiras", mu-ra-piš mi-iș-ri ù ku-du-ri ${ }^{16}$, referindo-se ao rei assírio, ilustra já não uma intenção, já não um programa, mas antes supõe um registo histórico, um enunciado que traduz algo já realizado e a recorrência e continuidade desse feito ${ }^{17}$. Tanto mișru como kudurru correspondem à ideia de fronteira ${ }^{18}$, de delimitação do território, que o rei assírio não reconhece porque a expectativa que sobre ele existe é a de que estenda esses limites, levando mais além o seu domínio.

A formulação traduz, por conseguinte, e em simultâneo, a consciência de um território que é variável e inconstante e a intenção de o expandir, que é concomitante à realeza assíria e à sua matriz ideológica. A Assíria, nos séculos XIV e XIII a. C., busca a expansão territorial e o poder real adquire uma feição imperialista. Esta evolução política e ideológica antecipa o quadro que reconhecemos no período neo-assírio ${ }^{19}$. O paradigma do estado territorial conquista assim uma dimensão imperialista e este último enunciado, "aquele que expande o território e a fronteira", de forma contracta, exprime a nova atitude na ideologia e na prática política assíria durante este período.

\section{O território e a fronteira: eixo estruturante na ideologia real}

A historiografia que se debruça sobre o período meso-assírio discute com frequência o conceito de império. Larsen ${ }^{20}$ sintetiza num interessante artigo sobre a tradição de império na Mesopotâmia as seis ocasiões em que tradicionalmente se reconhece a experiência imperial. O período entre 1350 e 1200 a. C. corresponde, na opinião do autor, a uma dessas ocasiões. Efectivamente, a Assíria adquire, durante esse período, uma nova configuração territorial e de estado submetido ao Mitanni torna-se 
a potência transeufratense mais importante, consolidando o seu núcleo territorial essencial em torno da Mesopotâmia setentrional.

Como já afirmámos atrás, o núcleo essencial desta nova configuração territorial é o país de Aššur, māt Aššur. A experiência imperial deste período meso-assírio é realizada a partir desse núcleo territorial, essencial na persistência de uma identidade assíria e na sua consciência enraizada que permanecerá em épocas posteriores, particularmente no período neo-assírio. Contudo, a identidade assíria e a sua consciência não dependem apenas da apropriação de um território e do sentido implícito da territorialidade; a dimensão histórica é fundamental no processo de construção e de afirmação da identidade. Nesse sentido, as inscrições reais oferecem exemplos dessa consciência histórica, que reflectem a apropriação e a sedimentação da identidade assíria, vincando a continuidade e a permanência.

É o caso da inscrição de Salmanazar ${ }^{21}$, onde, a propósito do Ehursagkurkurra $^{22}$, se recua até ao período paleo-assírio para lembrar que foi Ušpia quem o edificou e que foi Šamšî-Adad I quem o restaurou, muitos anos depois. A inscrição, que acentua a relação entre Salmanazar I e os reis paleo-assírios, apresentando-os como seus ancestrais ${ }^{23}$, procura justificar e legitimar a intervenção que o próprio soberano meso-assírio patrocinará sobre o templo. O tema central da inscrição é a intervenção no templo, que já por si se encontra no coração da identidade religiosa assíria. O texto descreve as obras realizadas mas acrescenta, no registo tipicamente auto-biográfico que caracteriza este género literário, que Salmanazar I vai mais longe e faz mais do que os seus antepassados. Estava, não obstante, alcançado o objectivo essencial, que consistia em estabelecer e vincar a relação directa entre o rei meso-assírio e os soberanos do reino da Alta Mesopotâmia.

A segunda inscrição de Salmanazar ${ }^{24}$ reincide sobre a mesma ideia. Desta vez, trata-se da reconstrução do templo de Ištar de Nínive. Šamšî-Adad I é de novo evocado, desta vez como o construtor do templo; Aššur-uballiț I é também apontado, mas como o soberano que patrocinou a sua reconstrução, muitos séculos depois. Ambos os reis são mencionados como antepassados ${ }^{25}$ de Salmanazar I.

Ambas as inscrições traduzem a intenção de construir e de preservar uma identidade política e cultural que passa pela associação aos soberanos do período paleo-assírio, afirmando a memória e continuidade históricas. A evocação e a apropriação histórica desse passado distante fundamentam e contribuem para a legitimação deste novo tempo e da sua vertente expansionista. Se, por um lado, verificamos que a Assíria se esforça por 
conquistar novos espaços, estranhos ao seu núcleo territorial referencial (māt Aššur), por outro, não deixamos de observar nas inscrições uma constante e recorrente indagação de um certo sentido de identidade que serve também o propósito de legitimar a conquista desses novos espaços e um outro sentido da territorialidade.

Os novos territórios são frequentemente descritos nas inscrições reais como espaços hostis, apresentando obstáculos naturais que dificultam a circulação e a passagem. Numa dessas inscrições ${ }^{26}$, alusiva a Salmanazar I, podemos ler: ana KUR ha-ni-gal-bat DU-ku-ma țu-di šap-šá-qi né-re-be mar-șu-ti lu ap-te. Propomos a seguinte tradução: «Fui até ao país de Hanigalbat, desbravei os caminhos adversos e os acessos difíceis". O outro, o país inimigo, é assim entendido como um território quase inacessível e que desafia o rei assírio, heroicizado ${ }^{27}$ nas inscrições. Desbravar esses novos e hostis territórios faz parte de um processo de domesticação da natureza até então indómita, cumprindo-se a missão civilizadora do rei assírio. Esta é a interpretação e a visão que podemos observar nos registos literários, as inscrições e os anais, que narram a conquista desses novos territórios e o alargamento das fronteiras que transformam o soberano assírio num murappiš mișri u kudurri, isto é, "aquele que expande os territórios e as fronteiras".

À conquista sucede a integração na ordem assíria, todavia, as formas que o sistema administrativo encontrou para enquadrar os novos territórios apresentam alguma versatilidade, traduzindo-se em respostas diferentes consoante os casos. Por outro lado, apesar da expansão territorial, estes novos espaços não deixam de ser vistos como exteriores e excêntricos relativamente ao núcleo essencial da Assíria (māt Aššur). Uma das consequências da conquista e da expansão territorial consiste na expressão ideológica de um novo tipo de soberania. As inscrições reais produzidas neste período exprimem de forma assaz assertiva uma atitude de domínio absoluto e universal. Após a narrativa da conquista, realizada contra todas as adversidades e enfrentando todos os inimigos, desde o Mitanni aos Hititas e aos Ahlamu, Salmanazar I declara de forma categórica a sua nova soberania: KUR.DIDLI-šu-nu a-bél ${ }^{28}$. Propomos a seguinte tradução: "tornei-me senhor de todas as terras". Para o rei assírio, trata-se indubitavelmente de um domínio universal, característica fundamental da soberania assumida neste período.

Tukultî-Ninurta I vai ainda mais longe na expressão dessa soberania universal. Numa das inscrições ${ }^{29}$ alusivas ao seu reinado, o soberano meso-assírio reúne uma constelação de títulos que afirmam essa soberania: 1) [tukultī- ${ }^{\circledR}$ in]-urta MAN KIŠ 2) [šarru dannu šar] KUR aš-šur 3) 
[šar MAN].MEŠ EN EN.MEŠ 4) [šar kibrāf] $\ulcorner 4(?)\urcorner$. Propomos a seguinte tradução: "Tukultî-Ninurta, rei do universo, rei poderoso, rei do país de Aššur, rei dos reis, senhor dos senhores, rei das quatro (regiões)". A ideologia real alcança neste registo o seu expoente máximo. Neste plano ideológico, o rei é o senhor da Assíria, do núcleo territorial que constitui a sua referência identitária, não obstante, ele é também o eixo essencial de uma soberania universal. Nesta formulação, identificamos duas lógicas complementares. Por um lado, uma lógica territorial. O rei assírio conquista e torna-se senhor dos novos territórios, dominando desde o país assírio até à totalidade do mundo conhecido. Ocorre, no entanto, uma segunda lógica, que não colide com a primeira. Trata-se de uma lógica política. $O$ rei assírio está no vértice superior do triângulo do poder numa expressão imperial. De forma superlativa, ele é descrito como o rei dos reis e o senhor dos senhores.

Esta nova visão assíria do poder, que antecipa verdadeiramente a realidade que reconheceremos de forma mais evidente alguns séculos mais tarde, no período neo-assírio, manifesta, por conseguinte, uma dupla consciência da territorialidade. Impõe-se de forma estruturante uma consciência do espaço assírio (māt Aššur), contudo, emerge também uma nova percepção territorial, a qual deriva compreensivelmente da anexação e domínio sobre os novos territórios. As titulaturas reais dos monarcas meso-assírios deixam perceber a coexistência dessas duas percepções da territorialidade. A primeira, vinculada ao "país de Aššur», acentua o carácter nacional e introspectivo da Assíria; a segunda, expressão das conquistas territoriais, reflecte o carácter dominador, inconstante e agressivo do país.

Nas inscrições reais, são frequentes as referências às fronteiras como limites mais ou menos ambíguos ${ }^{30}$ da ordem política assíria ${ }^{31}$. A enunciação dessas fronteiras deve ser entendida como uma intenção programática, não correspondendo necessariamente a um controlo político e territorial efectivo, material e permanente ${ }^{32}$. Não só o domínio político e militar sobre essas zonas de contacto era flexível como o controlo sobre o território estava condicionado pela sua natureza geográfica. O domínio sobre as zonas estépicas, com a circulação de populações nómadas, era frequentemente superficial.

Os textos são prolixos em enunciados, por vezes detalhados, indicando os territórios conquistados ${ }^{33}$ e fazendo a descrição geográfica, com a respectiva identificação política e cultural. A narrativa traduz a apropriação ideológica e política do espaço, correspondendo mais a uma intenção do que a uma realidade sustentada. O controlo territorial consiste num domínio concreto e efectivo do espaço, contudo, esse 
domínio revela-se frequentemente difuso no que concerne aos seus limites e às suas fronteiras. O espaço conquistado é muitas vezes descrito como um espaço difícil de transpor e como um território indómito. O rei ${ }^{34}$ é significativamente descrito como șa-bit KUR.KUR KÚR.MEŠ mu-re-piš mi-iș-ri, isto é, "aquele que conquista os territórios inimigos, o que expande as fronteiras".

Noutros contextos, observa-se o recurso a um outro termo para traduzir o conceito de fronteira, isto é, pāțu. É o caso de Tukultî-Ninurta $\left.\right|^{35}$, que, na inscrição, assinala os limites do seu poder justo e legitimado pelos deuses: a-di pa-[aț na'iri u pāt māt m]a- $\ulcorner k a-a n\urcorner$. Propomos a seguinte tradução: "até à fronteira de Nairi e à fronteira de Makan". Num tão vasto território, estas fronteiras apresentam-se quase simbolicamente, expressivas de um domínio apesar de tudo algo difuso. A noção de fronteira deve ser, por conseguinte, considerada neste contexto histórico e cultural. Estamos nos antípodas de uma compreensão geométrica deste conceito, a qual emergirá apenas com o estado moderno. A fronteira corresponde essencialmente a uma zona de transição, certamente difusa, entre duas entidades políticas distintas. Nesse sentido, esta fronteira consiste sobretudo num espaço não fechado e frequentemente de interacção cultural.

\section{A fronteira eufratense do império}

A oeste, o Eufrates, na sequência da hegemonia assíria alcançada sobre o Habur e o Balih, terá funcionado como uma fronteira natural e porventura também simbólica. Sendo verdade que o rio era sobretudo um factor de circulação e de comunicação, ao longo de um eixo longitudinal, ele constituía também, no plano latitudinário, um obstáculo e uma fronteira. Do ponto de vista simbólico e mental, o Eufrates impunha-se nesta época como um limite que, não sendo absoluto, confinava os territórios das grandes potências do tempo. Mencionamos, de novo, o tratado entre Šattiwaza e Suppiluliuma para ilustrar a importância do Eufrates como fronteira ${ }^{36}$. O rio é aí recorrentemente mencionado como a raia entre o Hatti e o Mitanni, observando-se pilhagens constantes nas suas margens. Foi assim entre o Hatti e o Mitanni e tornou a ser assim entre o Hatti e a Assíria, a nova potência trans-eufratense.

No século XIII a. C., é provável que o Eufrates tenha efectivamente funcionado como uma região de fronteira, ainda que não possamos estar certos da sua eficácia. Na verdade, até há pouco tempo atrás, não se registava na região do Médio Eufrates sírio confirmação arqueológica de 
uma fronteira efectiva, assinalável através da existência de sítios localizados na margem do rio. Todos os sítios arqueológicos identificados com uma ocupação meso-assíria correspondiam a uma região localizada entre - Habur e o Balih, a qual constituía o epicentro da presença assíria na jazira. Tall Qabr Abu al-'Atiq parece confirmar a ideia de que, contrariando os dados arqueológicos anteriores, e em consonância com as fontes textuais, o Eufrates terá funcionado, de facto, como fronteira ocidental do império meso-assírio.

Aline Tenu ${ }^{37}$ reconhece essa contradição ao afirmar: «pendant longtemps, les réticences à admettre une telle avancée assyrienne résidaient en partie dans le fait qu'en dépit de la documentation épigraphique, aucun établissement avec du matériel médio-assyrien n'avait été mis au jour sur l'Euphrate. C'est pourquoi pour beaucoup de chercheurs, la frontière assyrienne était fixée entre le Balih et l'Euphrate". A autora, no entanto, acrescenta em seguida: «la recherche archéologique recente engage désormais à revoir cette idée ${ }^{38}$. Certamente, Aline Tenu ${ }^{39}$ não conhecia então os trabalhos arqueológicos, ainda recentes ${ }^{40}$, que o PAMES (Projecto Arqueológico Médio Eufrates Sírio) tem desenvolvido em Tall Qabr Abu al-'Atiq, no entanto, tudo parece indicar que o estudo deste sítio poderá contribuir para uma revisão historiográfica da problemática da fronteira ocidental do império meso-assírio. Tall Qabr Abu al-'Atiq poderá configurar um dunnu, apresentando uma cerâmica de tipo administrativo médio-assíria. A suportar esta ideia, encontra-se ainda a localização geoestratégica do sítio, a qual sugere um controlo privilegiado do rio, instalado nas proximidades da entrada da garganta de Halabiya.

Contrariamente ao carácter lacónico dos dados de natureza arqueológica, as fontes textuais, designadamente as inscrições reais, são prolixas nas suas referências à fronteira eufratense ${ }^{41}$. Numa inscrição $0^{42}$ dedicada a Adad-nîrârî I, podemos ler: a-di a-ah ÍD pu-ra-at-ti. O enunciado, "até às margens do Eufrates", identifica um dos limites do território controlado pelo monarca assírio. Numa outra inscrição ${ }^{43}$, mais interessante, o rei Tukultî-Ninurta I vangloria-se de haver atravessado o Eufrates e de ter feito uma incursão pelas terras controladas pelo Hatti, tendo capturado 28800 inimigos, numa operação datada do início do seu reinado ${ }^{44}$. Podemos ler: iš-tu e-ber-ti ÍD pu-rat-te as-su-ha-ma a-na ŠÀ KUR-ia. Propomos a seguinte tradução: "conduzi(-os) desde o outro lado ${ }^{45}$ do Eufrates até ao interior do meu país". A formulação é interessante porque pressupõe três noções distintas. Identifica o "outro lado do Eufrates" como o país inimigo, o território onde o rei assírio terá vencido os hititas; refere o «interior do meu país", provavelmente querendo aludir ao māt Aššur, isto é, ao "país 
de Aššur»; finalmente, e de forma subjectiva, identifica o Eufrates como a fronteira entre o império hitita e o império assírio.

Compreende-se através da leitura deste enunciado que há a consciência de que o domínio assírio sobre o território e a sua percepção da territorialidade obedecem a uma gradação, quer no plano da apropriação mental quer no plano do seu controlo efectivo. Se o Eufrates constitui, pelo menos de forma subjectiva, a fronteira entre os dois impérios, a região transeufratense, e em particular a jazira, correspondem ao domínio assírio. Não obstante, a inscrição distingue subjectivamente entre o domínio assírio e o "país de Aššur", provavelmente referido neste contexto como o «interior do meu país».

\section{A expansão e a organização do império}

A expansão assíria no século XIII a. C. estrutura-se fundamentalmente em três direcções: a) norte e nordeste (Urartu); b) oeste e noroeste (regiões eufratenses); c) sul (Babilónia) ${ }^{46}$. Contudo, o eixo latitudinário, orientado para ocidente, em direcção à região eufratense, e em especial para as zonas dos vales do Balih e do Habur, revelou-se estrategicamente preponderante no processo expansionista assírio durante este período ${ }^{47}$. O conceito de império, com todas as reservas teóricas que a sua discussão pode envolver, é aplicável à época meso-assíria ${ }^{48}$. Observamos neste contexto um sistema que procura articular um centro com as suas periferias e que, de forma minimalista, é certo, tenta organizar numa lógica política, administrativa e socioeconómica os novos territórios, buscando assim a integração e a exploração económica desse espaço. A expansão assíria tem obviamente uma motivação económica e os seus limites naturais imediatos eram os vales dos rios Balih e Habur, afluentes do Eufrates. A localização geográfica da capital, Aššur, situada na margem direita do Tigre $^{49}$, favoreceu e impulsionou a expansão assíria para ocidente. A região que se estendia até ao Habur, situado cerca de $230 \mathrm{~km}$ a oeste da capital, transformava-se assim no hinterland natural de Aššur. Um território, o "país de Aššur», com o seu centro instalado na margem ocidental do Tigre, fazia naturalmente a sua expansão para ocidente, em direcção às terras irrigadas dos afluentes do Eufrates $^{50}$. Por outro lado, o valor económico da região era acrescentado também pelo facto da jazira ser atravessada por rotas comerciais que conduziam à Anatólia, à costa mediterrânica e à Babilónia ${ }^{51}$. 
A distância considerável entre o centro político e administrativo do império e as regiões agrícolas situadas a oeste constituía um problema. Tornava-se absolutamente necessário um sistema de comunicações terrestres entre o centro e a periferia ocidental. Hartmut Kühne defende a existência de uma estrada que, atravessando a estepe, ligava Aššur a Dur-Katlimmu, apontando diversos vestígios arqueológicos para apoiar a sua tese ${ }^{52}$. Apesar das dúvidas que subsistem acerca da existência dessa estrada, a verdade é que era vital um sistema de comunicações terrestres capaz de estruturar e de articular o centro político e administrativo do império com as regiões periféricas. Não obstante as convicções de Kühne, as fontes textuais são por enquanto evasivas e pouco têm ajudado na confirmação desta hipótese.

A conquista do território foi seguida de deslocação e de emigração de elites assírias, dando origem a um processo de colonização regional ${ }^{53}$. Lyon sugere a hipótese de, na zona do Balih, a instalação assíria ter sido antecedida por um fenómeno de progressivo abandono local ${ }^{54}$. Este processo alterou o modo de ocupação do território, doravante menos disperso ${ }^{55}$, mais concentrado em sítios de menor dimensão. O dunnu, espécie de entreposto administrativo e de gestão económica, torna-se o elemento estruturante dessa rede assíria de apropriação e controlo do território.

Esta elite assíria valoriza a propriedade fundiária. A posse da terra foi, aliás, instrumento de uma estratégia de afirmação do poder real por Aššur-uballiț I, no século XIV a. C. Nessa época, emerge uma nova categoria de proprietários, uma nova elite sócio-económica, fenómeno que se fica a dever à redistribuição fundiária. Estes dois fenómenos são concomitantes e reflectem uma relação de interesse mútuo entre o monarca e essa elite emergente. A conjunção entre o poder real e essa elite revelar-se-á estruturante no sistema social e político assírio. Apesar do aparente poder arbitrário da realeza e do estado assírios, o sistema de redistribuição de terras era fundamental para a estabilidade social, política e administrativa do império e esta elite, sobretudo nas províncias imperiais, constituía a base da administração local e o factor que fazia mover a economia agrária nesses territórios.

A expansão assíria dos séculos XIV e XIII a. C. obedece assim a uma motivação essencialmente económica. Embora os textos evidenciem naturalmente o imperativo ideológico e religioso da conquista, é o pragmatismo económico que justifica a iniciativa assíria. Na verdade, para os assírios, as duas lógicas eram concomitantes. O rei encetava uma guerra por ordem dos deuses e uma boa parte dos rendimentos que dela resultavam eram destinados aos templos e a uma aristocracia que 
beneficiava da redistribuição das terras conquistadas. Neste sentido, e no contexto deste equilíbrio político, o rei assírio era mais arbitral do que arbitrário, condicionado pelos poderes religiosos e pelas elites políticas e administrativas. Essa aristocracia vai associar-se ao empreendimento do estado, beneficiar dele, sendo também, contudo, factor fundamental na organização económica e administrativa dos novos territórios ${ }^{56}$.

Esta elite assíria, deslocada voluntariamente na jazira, beneficiária da conquista e da redistribuição da terra, mas também agente da exploração económica e da organização administrativa do território, ocupará ao longo do séc. XIII a.C. o lugar e o papel desempenhados até então pela classe de funcionários de origem mitânia ${ }^{57}$. Com a fixação dessa elite, nascerá e desenvolver-se-á uma rede provincial que estruturará a colonização. O sistema de administração assentava em pāhutu, províncias organizadas em torno de um centro urbano, que aglutinava os dunnu, com as suas terras de cultivo e a sua exploração agrária ${ }^{58}$. Tall Qabr Abu al-'Atiq estaria integrada numa organização deste tipo. A existência de terras agrícolas contíguas, a proximidade do Eufrates ${ }^{59}$, a localização estratégica do sítio, permitindo o controlo da entrada da garganta de Halabiya ${ }^{60}$, constituem factores que militam a favor da identificação do sítio como um dunnu. As duas tabuinhas cuneiformes encontradas, que permitem pensar num arquivo cuneiforme ${ }^{61}$ em Tall Qabr Abu al-'Atiq, e a presença abundante de cerâmica administrativa assíria sugerem a existência de uma elite ${ }^{62}$, que seria parte da rede administrativa regional.

\section{Notas}

(1) Sobre essa "Idade obscura» regista-se muito pouca informação, exceptuando, entre outros casos, algumas inscrições fragmentárias e certas referências epistolares. Cf. M.G. MASETTI-

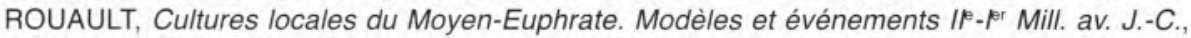
Turnhout, Brepols, 2001, p. 53.

(2) Cf. A. HARRAK, Assyria and Hanigalbat. A historical reconstruction of bilateral relations from the Middle of the fourteenth to the end of the twelfth centuries B.C., Hildsheim-Zürich-New York, Georg Olms Verlag, 1987, p. 7; Cf. A. TENU, L'expansion médio-assyrienne. Approche archéologique, Oxford, Archaeopress, 2009, p. 323.

(3) Cf. COHEN e WESTBROOK, Amarna Diplomacy. The beginning of international relations, Baltimore, The Johns Hopkins University Press, 2000, pp. 1-12.

(4) Cf. William MORAN, The Amarna Letters, Baltimore, The Johns Hopkins University Press, 1992.

(5) Cf. HARRAK, op. cit., p. 15.

(6) EA 17 é ilustrativa da concertação política e militar entre os dois estados contra o adversário comum. 
(7) Essa substituição torna-se muito clara em EA 16, quando o soberano assírio lembra ao faraó que tem um estatuto igual ao do rei de Hanigalbat. A semântica e o critério usado na escolha dos títulos reais têm, por outro lado, um óbvio significado político. O rei assírio vê-se a si mesmo e parece ser reconhecido no contexto internacional como "grande rei", "rei do país de Aššur ", para além de interpelar o faraó como «irmão". Todos os títulos têm uma leitura na lógica político-diplomática e têm, em princípio, alguma sustentação.

(8) Cf. Trevor BRYCE, The Kingdom of the Hittites, Oxford, Oxford University Press, 2005, p. 184.

(9) Cf. M. CHAVALAS, The Ancient Near East. Historical Sources in Translation, London, Blackwell Publishing, 2006, pp. 241-244. Šattiwaza casa com uma das filhas de Suppiluliuma, estreitando assim os laços políticos entre ambos e legitimando a anunciada intervenção hitita, destinada a entronizar o genro.

(10) Ibidem, p. 243.

(11) O programa de conquistas e de anexações territoriais desenvolvido a partir de Aššur-uballiț dá a consistência mínima ao novo paradigma ideológico assírio.

(12) Cf. HARRAK, op. cit., pp. 42-43; cf. J.N. POSTGATE, «The land of Assur and the yoke of Assur", World Archaeology, 23, n 3, 1992, p. 247.

(13) Este tipo de epítetos não é original deste periodo. Na realidade, já os encontramos com Šamšî-Adad I, num contexto em que o estado tem igualmente uma dimensão territorial vasta.

${ }^{(14)}$ A historiografia anglo-saxónica chama a esse território de referência "Assyria proper ": A.K. GRAYSON, Assyrian Rulers of the third and second Millennia BC (to 1115 BC), Toronto, University of Toronto Press, 2003, p. 203; Postgate define-a como o território inicialmente correspondente ao "triângulo assírio" na região de Nínive (POSTGATE, art. cit., p. 251).

(15) Liverani defende em geral, e não apenas no caso das titulaturas, designadamente a propósito da retórica que observamos nas inscrições e nos anais, que há sempre uma relação entre esta fraseologia exacerbada e a realidade; M. LIVERANI, Relaciones internacionales en el Proximo Oriente antiguo, 1600-1100 a. C., Barcelona, Ed. Bellaterra, 2003, p. 57.

(16) Encontramos esta perifrase, por exemplo, numa inscrição dedicada a Adad-nîrârî I (A.0.76.1), GRAYSON, op. cit., pp. 131-132.

(17) A forma participial, no sistema $\mathrm{D}$, de rapāšu(m) exprime neste caso a ideia de continuidade, assegurada pelo agente da acção que é o rei.

(18) O primeiro termo, mișru, parece traduzir principalmente a ideia de linha que separa dois espaços; já kudurru traduz o marco, a pedra usada para assinalar uma propriedade ou uma fronteira. A amplitude semântica de mișru leva-nos, contudo, um pouco mais longe, uma vez que o termo pode também significar território. Nesse sentido, traduz-se geralmente a associação dos termos como dois conceitos distintos, embora paralelos, isto é, território e fronteira.

${ }^{(19)}$ Cf. Susan POLLOCK e Reinhard BERNBECK (eds.), Archaeologies of the Middle East. Critical perspectives, Oxford, Blackwell Publishing, 2005, p. 23.

(20) Cf. Mogens Trolle LARSEN, "The tradition of the empire in Mesopotamia", in Power and Propaganda: symposium on ancient empires, Copenhagen, Akademisk Forlag, 1979, pp. 75-103. Define império desta forma: «I would suggest that na empire be defined as a supernational system of political control, and such a system may have either a city-state or a territorial state as its center" (ibidem, p. 91).

(21) A.0.77.2. Cf. GRAYSON, op. cit, p. 189.

(22) Trata-se do templo de Aššur, edificado na cidade de Aššur. 
${ }^{(23)} \mathrm{O}$ termo usado é $a b u$, isto é, pai.

${ }^{(24)}$ A. 0.77.17. Cf. GRAYSON, op. cit., p. 206.

(25) Relativamente a Šamšî-Adad I, é desta vez usada uma perífrase: LUGAL a-lik pa-ni-ia. Poderiamos traduzir literalmente por "o rei que caminhou antes de mim», mas o significado efectivo refere-se ao “rei, meu antepassado». Com Aššur-uballiț I, é usado o termo abu, que já tínhamos encontrado antes.

${ }^{(26)}$ A.0.77.1. Cf. GRAYSON, op. cit., p. 183.

(27) Cf. F. CARAMELO, "Os jardins reais na Assíria. Reprodução idealizada da natureza", Revista da Faculdade de Ciências Sociais e Humanas, n 15, 2002, pp. 85-92.

${ }^{(28)}$ A 0.77 .1 . Cf. GRAYSON, op. cit., p. 184.

(29) A. 0.78.3. Ibidem, p.241.

(30) Por vezes, podiam ser os elementos geográficos, designadamente os rios, a funcionar como fronteiras entre as entidades político-administrativas. É o caso do Eufrates, que, nas inscrições reais deste período, é recorrentemente mencionado como fronteira.

(31) Liverani sugere a existência de um equilíbrio territorial e político, apesar da mobilidade das fronteiras nesta segunda metade do II milénio a. C. (Cf. LIVERANI, op. cit., pp. 81-87).

${ }^{\left({ }^{32}\right)}$ A questão da fronteira envolve uma dimensão semântica que não podemos ignorar. Em inglês, regista-se claramente a distinção entre "border ", "boundary" e ufrontier". Se o primeiro termo parece apontar sobretudo para uma ideia de limite político e administrativo preciso, o segundo já se revela mais ambíguo, embora ainda suponha essa divisória entre entidades políticas, culturais ou geográficas. Já o terceiro termo sugere uma zona de transição entre duas entidades, que não estão necessariamente em contacto directo. (Cf. Bradley PARKER, "At the edge of empire: conceptualizing Assyria's Anatolian frontier ca. 700 BC", Journal of Anthropological Archaeology, 21, $n^{\circ} 3,2002$, p. 373). Ver sobre esta questão o estudo teórico de Prescott (Cf. John Robert Victor PRESCOTT, Boundaries and Frontiers, London, Croom Hel, 1978, pp. 13-32). Sagona, seguindo Prescott, estabelece três conceitos fundamentais. Entende "boundary" como a linha que divide duas entidades políticas; "border" ou "borderland" como a área contígua a essa linha, de ambos os lados; e "frontier " como uma zona ou território que se estende além dessa linha ou área e onde se pode observar tanto o contacto e mistura como o conflito (Cf. Antonio SAGONA; Claudia SAGONA, Archaeology at the North-East Anatolian Frontier Geography, I An Historical Geography and a field survey of the Bayburt Province, Herent, Peeters, 2004, p. 15). $\mathrm{Na}$ realidade geral que conhecemos na Mesopotâmia, e particularmente no caso do período meso-assírio, este conceito de fronteira, de geometria variável, parece aplicar-se bem.

(33) Mencionados como KUR (mātu).

(34) Neste caso, é Tukultî-Ninurta I. A.0.78.2, cf. GRAYSON, op. cit., p. 240.

${ }^{(35)}$ A.0.78.2. Ibidem, p. 240.

${ }^{(36)}$ Cf. M. CHAVALAS, op.cit., pp. 241-244.

(37) Cf. A. TENU, "Du Tigre à l'Euphrate: la frontière occidentale de l'empire médio-assyrien", $S A A B, 15,2006$, p. 166.

(38) Ibidem, p. 167.

(39) Aline Tenu tem-se dedicado a estudar esta problemática da fronteira ocidental, sobretudo numa perspectiva arqueológica. A sua abordagem é, não obstante, incompleta, na medida em que atenta sobretudo sobre as regiões do Alto Eufrates sírio e do Médio Eufrates iraquiano, na medida em que atenta sobretudo sobre as regiões do Alto Eufrates sírio e do Médio Eufrates iraquiano (Aline 
TENU, "Le Moyen Euphrate à l'époque médio-assyrienne", in Christine Kepinski, Olivier Lecomte, Aline Tenu, Studia Euphratica Le Moyen Euphrate iraquien révélé par les fouilles préventives de Haditha, Paris, De Boccard, 2006, pp. 217-245; Aline TENU, "La diffusion de la culture des vainqueurs: l'exemple médio-assyrien (XIVe-Xle siècles)", in P. Rouillard (éd.), Mobilités,immobilismes. L'emprunt et son refus, Paris, De Boccard, 2007, pp. 223-233). A zona do Médio Eufrates sírio tem permanecido ausente destas abordagens, em particular das que tentam cruzar as perspectivas histórico-textual e arqueológica (cf. Hartmut KÜHNE, "The Assyrians on the Middle Euphrates and the Hābūr", in Mario Liverani (ed.), Neo-Assyrian Geography, Roma, Università di Roma, Dipartimento di scienze storiche, archeologiche e antropologiche dell'Antichità, 1995, pp. 69-85). Regista-se uma divergência entre a documentação de carácter epigráfico e os dados de natureza arqueológica, a qual tem suscitado dúvidas quanto à identificação de uma ocupação assíria nesta zona. Apesar de a documentação epigráfica mencionar de forma recorrente essa fronteira assíria na região do Médio Eufrates sírio, a verdade é que até recentemente a arqueologia parecia não o confirmar. A investigação arqueológica sobre a expansão meso-assíria na Síria tem centrado a sua atenção nos vales dos rios Balih e Habur. Podemos destacar as escavações que têm tido lugar em Tall Sabi Abyad (cf. P. AKKERMANS, "The fortress of Ili-pada. Middle Assyrian architecture at Tell Sabi Abyad, Syria", Subartu, XVII, 2006, pp. 201-211), Khirbet esh-Shenef (cf. K. BARTL, "Khirbet esh-Shenef a late Bronze Age settlement in the Balikh valley, northern Syria", Akkadica, 67, 1990, pp. 10-32), Tall Barri (P. E. PECORELLA (ed.), Tell Barri/Kahat, 2, Roma, CNR - Istituto per gli Studi Micenei ed Egeo-Anatolici, 1998), Tall al-Hamidiya (S. EICHLER; M. WÄFLER; D. WARBURTOM, Tall al-Hamidiya, 2, Freiburg, Universitatsverlag Freiburg, 1990), Tall Khuera (W. ORTHMANN et al., Ausgrabungen in Tell Chuera in Nordost-Syrien, Saarbrüken, Saarbrucker Druckerei und Verlag, 1995), Hammam et-Turkman (Maurits van LOON, Hammam et-Turkman I, Istanbul, Nederlands Historisch-Archaeologisch Instituut, 1988), Dur-Katlimmu (cf. Hartmut KÜHNE, "Gedanken zur Historischen und Städtebaulichen Entwicklung der Assyrischen Stadt Dür-Katlimmu", in Paolo Matthiae et al. (ed.), Resurrecting the Past. A Joint Tribute to Adnan Bounni, Istanbul, Nederlands Historisch-Archaeologisch Instituut, 1990, pp. 153-169), Tall Fakhariyah (B. HROUDA, "Tell Fecherije. Die Keramik», ZA, 54, 1961, pp. 201-239).

${ }^{(40)}$ Embora o PAMES tenha desenvolvido trabalhos de prospecção na zona da garganta de Halabiya, incluindo Tall Qabr Abu al-'Atiq, entre 2005 e 2007, a escavação arqueológica neste sítio só teve início em 2008.

(41) Os estudos efectuados sobre o material de natureza epigráfica têm prevalecido sobre a abordagem arqueológica. São os casos, entre vários outros, de P. MACHINIST, «Provincial Governance in Middle Assyria and some new texts from Yale", Assur, 3/2, 1982, pp. 1-37, centrado na análise da administração provincial meso-assíria; cf. HARRAK, op.cit., com o seu importante estudo sobre as relações entre a Assíria e o Hanigalbat, nos sécs. XIV e XIII a.C.; de M. LUCIANI, "On Assyrian Frontiers and the Middle Euphrates", SAAB, 13, 1999-2001, pp. 87-114, sobre a fronteira assíria e o Médio Eufrates.

${ }^{(42)}$ A. 0.76.3. Cf. GRAYSON, op. cit., p. 136.

(43) A. 0.78.23. Ibidem, p. 272.

(44) Cf. J. FREU, «De la confrontation à L'entente cordiale: les relations assyro-hittites à la fin de l'âge du Bronze (ca. 1250-1180 av.J.C.", in Gary Beckman et al. (ed.), Hittite Studies in Honor of Harry A. Hoffner Jr. on the Occasion of His 65th Birthday, Winona Lake, Eisenbrauns, 2003, p. 106.

${ }^{(45)}$ O termo ebertu(m) significa o outro lado ou a outra margem do rio.

${ }^{(46)}$ Cf. P. MACHINIST, art. cit., p.13.

${ }^{(47)}$ Cf. M. LUCIANI, art. cit., p. 88. 
(48) Lembremos mais uma vez LARSEN, op. cit., pp. 75-103.

(49) Ao contrário de outras capitais assírias, que se situavam na margem oposta. Cf. KÜHNE, art. cit., p. 69, e KÜHNE, «Dūr-katlimmu and the Middle-Assyrian Empire», Subartu, VII, 2000, p. 272.

(50) Trata-se de uma região onde a agricultura era viável a sul da linha dos $200 \mathrm{~mm}$ de pluviosidade.

${ }^{(51)}$ Cf. Jerry D. LYON, «Middle Assyrian Expansion and Settlement Development in the Syrian Jazira: the View from the Balikh Valley", in R. M. Jas (ed.), Rainfall and Agriculture in Northern Mesopotamia, Istanbul, Nederlands Historisch-Archaeologisch Instituut, 2000, p. 91.

${ }^{(52)}$ Cf. KÜHNE, art. cit., p. 71.

(53) Maria Grazia Masetti-Rouault, em contrapartida, fala da deportação de elites de proprietários de terras na Síria setentrional e também na jazira, o que terá facilitado a colonização; cf. MASETTI-ROUAULT, "Syriens et Assyriens dans la Djéziré, XIVème-IXème siècle av. J.-C.", Subartu, IV, 2, 1998, p. 223.

${ }^{(54)}$ Cf. LYON, art. cit., p. 104.

${ }^{(55)}$ Cf. Aline TENU, «La diffusion de la culture des vainqueurs: l'exemple médio-assyrien (XIVe-Xle siècles)", p. 226.

${ }^{(56)}$ Cf. MASETTI-ROUAULT, op. cit., p. 58.

(57) Cf. MASETTI-ROUAULT, art. cit., p. 227.

${ }^{(58)}$ A exploração agrícola era a actividade mais importante do dunnu e a entidade que o administrava era quem tinha a propriedade da terra (F. A. M. WIGGERMANN, "Agriculture in the Northern Balikh Valley. The Case of Middle Assyrian Tell Sabi Abyad", in R.M. Jas (ed.), op. cit., 2000, p. 174).

(59) Um paleo-meandro do rio assinala ainda a sua presença justamente na base do tell.

${ }^{(60)}$ Não se deve descurar também a existência do "canal de Semíramis" (Francisco CARAMELO, "Les deux grands canaux de la rive gauche du Moyen Euphrate - Dawrîn et Sémiramis. La prospection du canal Sémiramis dans le cadre du PAMES", Estudos Orientais, X, 2009, pp. 147-165), alguns quilómetros a jusante, e que, caso estivesse activo na época, poderia ter o seu papel na circulação fluvial e sobretudo na articulação da região com o Habur, contribuindo para o escoamento da produção agrícola local. É, no entanto, apenas uma hipótese especulativa, uma vez que não se regista qualquer dado de natureza arqueológica ou textual que permita confirmar a sua utilização nesta época.

(61) Tal como acontece noutros casos que ilustram a actividade administrativa, económica e até militar, como são exemplo: Tall Bderi (S.M. MAUL, Die Inschriften von Tall Bderi, Berlin, Dietrich Reimer Verlag, 1992); Tall Țābān (S.M. MAUL, Die Inschriften von Tall Taban (Grabungskampagnen 1997-1999). Die Könige von Tabetu und das Land Mari in mittelassyrischer Zeit, Tokyo, Kokushikan University Press, 2005); Tall Seh Hamad (cf. Eva CANCIK-KIRSCHBAUM, Die mittelassyrischen Briefe aus Tall Šeh Hamad, Berlin, Dietrich Reimer Verlag, 1996).

(62) O selo-cilindro encontrado durante a campanha de 2009, cuja publicação se aguarda, poderá indiciar a presença dessa elite. 